\title{
OPTIMIZATION OF THE TRANSPORT NETWORK STRUCTURE BY THE ANT COLONY METHOD
}

\author{
Sihem BOURI, Abdelhalim BENMANSOUR \\ Materials and Renewable Energy Research Unit (URMER), University Aboubekr Belkaid Tlemcen BP 119 - 13000, Algeria, \\ E-mail: Sihem.bouri@mailuniv-tlemcen.dz, halim.benmansour13@gmail.com
}

\begin{abstract}
The optimization of the network structure amounts to structuring an optimal configuration among several by modeling it with a graph that admits nodes and edges. The determination of the optimal graph is to determine the optimal connection of the system by which its conventional cost is minimal. This article discusses the optimization of the transport network structure using ant colony method.
\end{abstract}

Keywords: Optimization, Transport network, Ant colonies, Structure of network.

\section{INTRODUCTION}

The problem of optimizing parallel serial systems has been extensively studied using iterative methods such as Prim Krustal and Djikstra and recently, genetic algorithms and ants. Few studies have used Ant Colony Optimization (ACO) to solve NP-Hard optimization problems. However, given the large size of the NP-Dur search space, the latter is a suitable subject for study by ACO methods.

In this paper, we use a new meta-heuristic based on ant colonies to solve the problem of optimizing the structure of electrical grids known generally as the redundant NP-Dur (combinatorial problem of redundancies).

\section{SUBJECT}

Consider a configuration of a virtual network of $\mathrm{S}$ branches, the conventional cost is given by:

$Z=\sum_{S} Z_{i j}$

$Z_{i j}$ : Conventional cost of the branch $i j$.

$Z_{i j}=\left[a_{e x p}+a_{a m o r t}\right] \cdot K_{i j}+Y_{A A_{i j}}$

Where:

$K_{i j}$ : Investment of the line $(i j)$.

$a_{\text {exp }}:$ Exploitation rate.

$a_{\text {amort }}:$ Amortization rate.

$Y_{A A_{j j}}$ : Energy losses in the line (ij).

To simplify the equations of the problem, one poses:

$a=a_{\exp }+a_{\text {amort }}$

$K_{i j}=\left\lfloor A+B F_{i j}\right\rfloor \cdot L_{i j}$

Where;
A: Represents an investment component that does not depend on (section, pylon, foundation) and is expressed in $[D A / K m]$.

$B$ : Coefficient expressed in $\left[D A / K m \mathrm{~mm}^{2}\right]$.

$F_{i j}$ : Conductor section $\left[\mathrm{mm}^{2}\right]$.

$L_{i j}$ : Length of the line $(i j)[K m]$.

$Y_{i j}=3 I_{i j}^{2} R_{i j} \tau C_{0}$

$\tau$ : Maximum power loss time in $[h]$.

$C_{0}$ : Cost of one $K W h$ of the energy losses in $[D A / K W h]$.

$I_{i j}$ : Maximum current on the branch $(i j)$ in $[A]$.

$R_{i j}$ : Resistance of the line $(i j)$ in $[\Omega]$.

$R_{i j}=\rho \frac{L_{i j}}{F_{i j}}$

$\rho:$ Resistivity of the conductor $\left[\Omega \cdot \mathrm{mm}^{2} / \mathrm{Km}\right]$.

With regard to the mesh configurations of transport, the economic section of the conductors is calculated by the economic current according to the mathematical model:

$F_{i j}=\frac{I_{i j}}{J_{\text {éco }}}$

$Z_{i j}=a\left(A+B \frac{I_{i j}}{J_{\text {éco }}}\right) \cdot L_{i j}+3 \rho \tau C_{0} I_{i j} L_{i j} J_{\text {éco }}$

With:

$$
\begin{aligned}
& J_{\text {éco }}=\sqrt{\frac{\left(a_{\text {exp }}+a_{\text {amort }}\right) B}{3 \rho \tau C_{0}}=\sqrt{\frac{a B}{3 \rho \tau C_{0}}}} \\
& Z_{i j}=\left(A+\frac{B}{J_{\text {éco }}} I_{i j}\right) L_{i j}+3 \rho \tau C_{0} I_{i j} L_{i j} J_{\text {é } c o} \\
& Z_{i j}=a A L_{i j}+\left(\frac{a B}{J_{\text {éco }}}+3 \rho \tau C_{0} J_{\text {éco }}\right) I_{i j} L_{i j} \\
& Z_{i j}=\hat{\mathrm{A}} L_{i j}+\beta I_{i j} L_{i j}
\end{aligned}
$$


With:

$\hat{\mathrm{A}}=a A$

$\beta=\frac{a B}{J_{\mathrm{e} c o}}+3 \rho \tau C_{0} J_{\text {éco }}$

If:

$\hat{A}, \beta=$ constante

$Z_{i j}=\left\{\begin{array}{c}0, s i / I_{i j}=0 \\ \hat{\mathrm{A}} L_{i j}+\beta I_{i j} L_{i j}, s i / I_{i j}>0\end{array}\right.$

The conventional cost for a network configuration is as follows:

$Z\left(I_{i j}\right)=\sum_{i} \sum_{j} Z_{i j} X_{i j}$

$X_{i j}=\left\{\begin{array}{l}0, \text { for } I_{i j}=0 \\ 1, \text { for } I_{i j}>0\end{array}\right.$

From the mathematical formulation, we see that the determination of the optimal configuration of the network is to find a current set equal to the zero value, this justifies the nonexistence of the branch ij in the connection diagram of the network for which the cost conventional $Z\left(I_{i j}\right)$ is minimal.

The function $Z\left(I_{i j}\right)$ is interrupted on the point $I_{i j}=0$ and it consists of two components:

The first:

$\hat{\mathrm{A}}\left\{\sum_{i} \sum_{j} L_{i j}\right\}$

which depends on the sum of the existing branches in the configuration.

The second:

$\beta\left\{\sum_{i} \sum_{j} I_{i j} L_{i j}\right\}$

which depend on the sum of the product of the current $I_{i j}$

by the lengths $L_{i j}$.

Determining the optimal configuration of a network results in the determination of the currents $I_{i j}$ so that the conventional cost of the network is:

$Z\left(I_{i j}\right)=\sum_{i}^{n} \sum_{j}^{m_{i}} X_{i j}\left\{\hat{\mathrm{A}} L_{i j}+\beta I_{i j} L_{i j}\right\}$
With:

$$
\sum_{j}^{m_{i}} I_{i j}=\left\{\begin{array}{c}
I_{i} s i, i=1 \\
n s i, i \neq j, I_{i j}>0
\end{array}\right.
$$

For which:

$I_{i}$ : Current of the charge or of the source in point $i$.

$n$ : Number of network nodes.

$m_{i}$ : Number of nodes connected directly with the node $i$.

$\sum_{j}^{m_{i}} I_{i j}$ : Sum of incoming and outgoing currents of the node $i$ Kirchhoff's law.

For one configuration at $\eta$ nodes, the number $S$ of currents unknowns $I_{i j}$ will be:

$S=n(n-1)$

This number of currents given by (18) derives from the fact that there are two currents in each branch $I_{i j}$ and $I_{i j}$ in reality we can neglect the residual currents coming from the charge towards the source, and according to the first law of Kirchhoff we will have (n-1) equation.

So, for an open network of $\mathrm{n}$ nodes, we will have (n-1) branches, whose conventional cost of the variable $I_{i j}$ is non-linear, and its modeling is of the following form:

$Z=\left(I_{i j}\right)=\left\langle Z_{1}+Z_{2}\right\rangle \quad$ for $\quad I_{i j}>0$

$Z_{2}=\beta\left(\sum_{i}^{n} \sum_{j}^{m_{i}} I_{i j} L_{i j}\right)$

$\mathrm{Z}_{1}$ : Component relating to the investment and proportional to the length of the lines.

$\mathrm{Z}_{2}$ : Component relating to power losses in the network. So, we can say that the objective function:

Minimize

$\operatorname{MinZ}\left(I_{i j}\right)=\sum_{i}^{n} \sum_{j}^{m_{i}} X_{i j}\left\{\hat{\mathrm{A}} L_{i j}+\beta I_{i j} L_{i j}\right\}$

Subject to

$\operatorname{MinZ}\left(I_{i j}\right) \geq \operatorname{Min}\left(\sum_{i}^{n} \sum_{j}^{m_{i}} X_{i j}\left|\hat{A} L_{i j}\right|+\left|\beta I_{i j} L_{i j}\right|\right)$

\section{METHODS}

\subsection{Theory of graphs}

In the network structure, a configuration is a set of graphs. A graph is defined as a topological construction of a set of points or vertices of an industrial system [2], the conduct 
connecting these points, for example, an electrical network (generator node, load node) constitutes a structure of branches between them. In modeling, we designate a graph of nodes and branches by: $\mathrm{G}(\mathrm{N}, \mathrm{E})$

We say that a topological construction is complete if the graph in which the set of pairs of nodes is connected by a pipe that is to say (branches).

\subsubsection{Example}

Consider the following complete configuration consisting of four (4) nodes with six (6) branches.

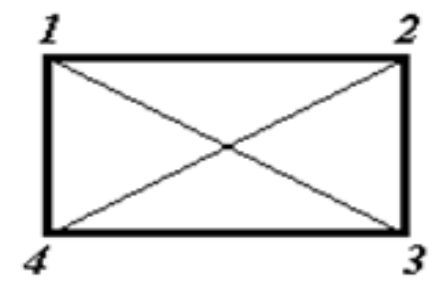

Fig.1 Four-node network

$$
\begin{aligned}
& N=4 \quad 01,02,03, \text { et } 04 . \\
& E=6 \quad(12),(23),(34),(41),(24),(13) .
\end{aligned}
$$

This leads us to model the complete topology by:

$S=\frac{n(n-1)}{2}$

A tree is the graph of a topology without loop (cycle). By the same nodes we can determine different trees.

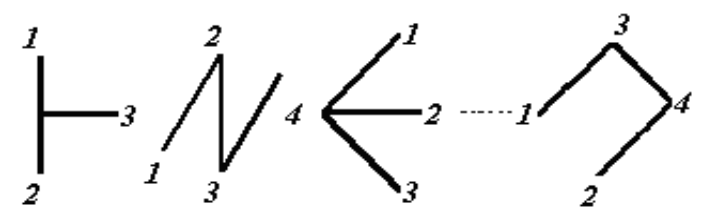

Fig.2 Possible trees

A tree of nodes to:

$S=(n-1)$

$N=4$ so $S=4-1=3$ branches.

If we add an arc to a tree, we create an additional branch, we will have a graph with a loop.

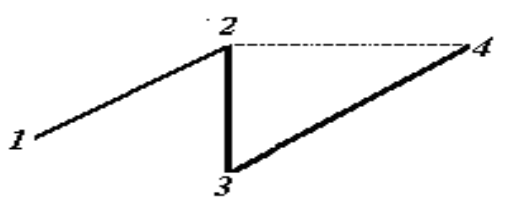

Fig. 3 Tree with buckle
If we remove an arc from the tree, we get illogical schemes.

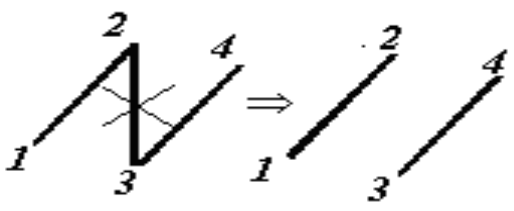

Fig. 4 Incomplete schema

According to Cayley's theorem, with $\mathrm{n}$ vertices, the number of trees that can be formed is determined by:

$$
S=(n)^{n-2}
$$

As an example, a topology formed by 04 vertices $n=04$, we have a complete graph:

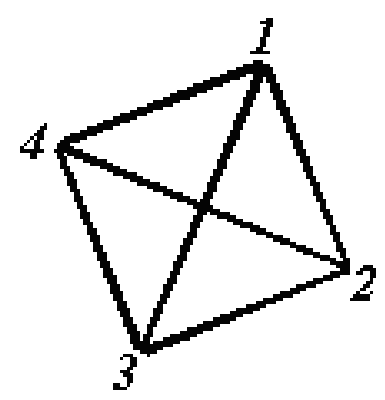

Fig. 5 Complete graph

But with $c=4^{(4-2)}=16$ different trees

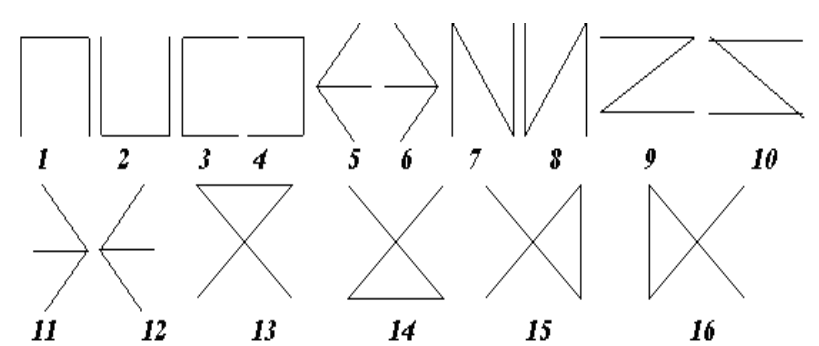

Fig.6 Different trees of a four-way network

\subsection{Presentation of the electrical network}

Transport subsystem (Line HV): Makes the basis of a tree configuration whose voltage level is the same. Then these lines are placed in parallel and try to pass the energy from the upstream point to the downstream point.

Transformation subsystem (Transformer HV/MV): This subsystem consists of a set of parallel transformers whose capacity or total performance is the sum of the performances of the different versions and types of transformers, the characteristic that changes is the level of HV / MV voltage. 
Transport subsystem (Line MV): The transport subsystem is usually based on medium voltage lines that supply medium voltage customers. The configurations are always arborescent. These lines are placed in parallel.

The transport subsystem is coordinated with HV line, HV / MV transformer and MV line (Fig. 1)

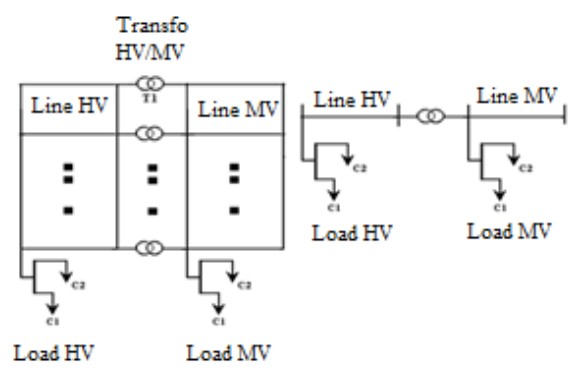

Fig. 7 Subsystem transport

\subsection{Application of the ACO algorithm}

Ant colony algorithms are based on the collective behavior of pheromone deposition and tracking observed in ant colonies. A colony of simple agents (ants) communicates indirectly via dynamic modifications of their environment (the pheromone tracks) and thus builds a solution to a problem, relying on their collective experience.

Our optimization problem to solve is to optimize an objective function:

$>$ Minimize the cost of the structure of the transport networks.

$>$ Under stress that the connection must be tied without breaking and that the power transits of the structure must be balanced (regarding the power flow).

In other words, it is a matter of selecting the best combination of the lines (whose global path is the shortest from the point of view of cost) without the connection of the tree being closed.

Lines can be selected in any combination among those that are theoretical and real.

In order to apply the ACO to the problem of optimizing the structure is virtually identical to that of the VSP, the problem is modeled by a graph $\mathrm{G}=(\mathrm{V} ; \mathrm{E})$ whose vertices correspond to the different nodes or consumers to affect by a sign (+) or producers assign by a sign (-) and whose edges represent the paths (power lines) connecting the different nodes and their corresponding characteristics. At each edge is also associated a weight according to the quality of the line (capacity, section, current and length) to which they lead.
The choice is made based on:

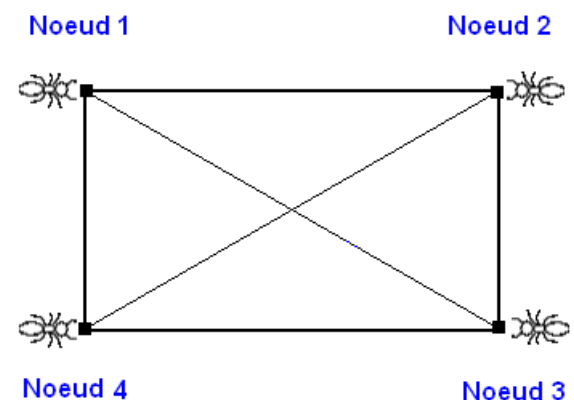

Fig. 8 Graph model

The ants are guided during the construction of a solution by the heuristic information specific to the problem $\eta$ which is inversely proportional to the length of the path (the ants prefer the choice of the short lines) and the pheromone rate (experiment of the other ants):

$\eta_{i j}=S_{i j} / L_{i j}$

$L_{i j}$ : represents the associated length between nodes $\mathrm{i}$ and $\mathrm{j}$ of the network.

$S_{i j}$ : represents the section of the associated length between nodes $i$ and $j$ of the network.

The algorithm is designed as follows:

$\mathrm{m}$ ants are initially positioned on the nodes representing the network or the graph. Each ant represents a configuration or a possible structure (tree) of the electrical network. This configuration consists of $\mathrm{n}-1$ nodes forming the tree or the vertebra of the electrical network system, each node $i$ communicated with the n-1 node of the network looped theoretically in turn the node $i$ can encompass the departure and arrival lines are in parallel. The ki line of each pair of lines are chosen in any combination from the possible number of lines of the graph which is:

$S=\frac{n(n-1)}{2}$

So, each ant builds a solution a tree, an ant placed on a node $i$ chooses a destination to another node $\mathrm{j}$ by applying a state transition rule given by:

$$
\begin{aligned}
& J=\left\{\begin{array}{l}
\arg \max _{m \in A C_{i}}\left(\left[\tau_{i m}\right]^{\alpha}\left[\eta_{i m}=\frac{S_{i m}}{L_{i m}}\right]^{\beta}\right) \text { if } q \leq q_{o} \\
J \quad \text { Autre }
\end{array}\right. \\
& p_{i j}=\left\{\begin{array}{l}
\frac{\left[\tau_{i j}\right]^{\alpha}\left[\eta_{i j}=\frac{S_{i j}}{L_{i j}}\right]^{\beta}}{\sum_{m \in A C_{i}}\left[\tau_{i m}\right]^{\alpha}\left[\eta_{i m}\right]^{\beta}} \text { if } j \in A C_{i} \\
\mathbf{0} \quad \text { Autre }
\end{array}\right.
\end{aligned}
$$


$\alpha$ : Represents the relative importance of the pheromone trail.

$\beta$ : Represents the relative importance of heuristic information

$\eta_{i j}=\frac{S_{i j}}{L_{i j}}$

$L$ : Represents the length of the line $(i, j)$

$S:$ Represents the section of the line $(i, j)$

$A C i$ : Represents all the rows (theoretical and real) existing for the graph.

$Q$ : Random number generated between 0 and 1 .

The parameter qo determines the relative importance of the exploitation: each time an ant on a node i must choose a destination towards a node $\mathrm{j}$ which defines a line $\mathrm{ij}$, first generates a random number $0 \leq \mathrm{q} \leq 1$.

The search process ends when the ant reaches the last node without returning to the starting node by forming a connection with all nodes (stop at node n-1) while forming the tree or vertebra it is a solution, this instruction is given by the Test List Tabu (virtual memory).

If the value of $\mathrm{q} \leq \mathrm{q}_{0}$ then the best edge (line) is selected according to the relation (27) (exploitation), otherwise an edge is chosen according to the relation (28) (skewed exploration).

The update of the pheromone consists of two phases:

- Local update

- Global update.

During the construction of a solution, the ant modifies the amount of pheromone on the edges (lines) visited by the application of the update rules.

The local update is introduced to avoid premature convergence and reduces the amount of pheromone on the edge connecting one node $i$ with another node $j$ (the line ij) so as to discourage the next ant from choosing the same destination during the same cycle. The local update is given by:

$\tau_{i j}^{N e w s}=(1-\rho) \tau_{i j}^{A n c i e n t}+\rho \Delta \tau_{i j}$

Where $\rho$ is a coefficient so that $(1-\rho)$ represents the evaporation of the pheromone trace and $\tau$ o is an initial value of the intensity of the pheromone trace.

Once all the ants have chosen their structure during a cycle, the amount of pheromone on the edges belonging to the best solution of the cycle (better ant) is reinforced again by applying the rule of global update.

$\tau_{i j}^{\text {new }} \rightarrow(1-\rho) \tau_{i j}^{o l d}+\rho \tau_{0}$
The final solution is the best solution found during all the cycles and it is obviously the one that satisfies the constraint of the tree connected to all the nodes, then with the most optimal structure from the point of view cost.

\subsection{Description of the algorithm}

STEP 1. Initialize:

Set $\mathrm{t}:=0\{\mathrm{t}$ is the time counter $\}$,

For each bow (i,j) make an initial value $\tau \mathrm{ij}(\mathrm{t})$ and do $\Delta \tau \mathrm{ij}$ $(\mathrm{t}, \mathrm{t}+\mathrm{n}):=0$,

Place $b_{i}(t)$ ants on each node $i\{b i(t)$ is the number of the ants on each node $i$ at time $t\}$,

Set $\mathrm{s}:=1\{\mathrm{~s}$ is the indexed tabu list $\}$

For $\mathrm{i}:=1$ to $\mathrm{n}$ do

For $\mathrm{k}:=1$ to $\mathrm{b}_{\mathrm{i}}(\mathrm{t})$ do

$\operatorname{tabu}_{\mathrm{k}}(\mathrm{s}):=\mathrm{i}$ \{Node of start is the $1^{\mathrm{st}}$ element of the tabu list for the $\mathrm{k}^{\text {th }}$ ant $\}$.

STEP 2. Repeat until tabu list is full \{this step is repeat (n1) time\}

2.0. Set $\mathrm{s}:=\mathrm{s}+1$

2.1. For $\mathrm{i}:=1$ to $\mathrm{n}$ do $\{$ For each node $\}$

For $\mathrm{k}:=1$ to $\mathrm{b}_{\mathrm{i}}(\mathrm{t})$ do $\left\{\right.$ For each $\mathrm{k}^{\text {th }}$ ant on the node $\mathrm{i}$ not moved yet

Choose the node $\mathrm{j}$ to move with probability $\mathrm{p}_{\mathrm{ij}}(\mathrm{t})$

$$
p_{i j}(t)=\left\{\begin{array}{l}
\frac{\left[\tau_{i j}\right]^{\alpha}\left[\eta_{i j}=\frac{S_{i j}}{L_{i j}}\right]^{\beta}}{\sum_{m \in A C_{i}}\left[\tau_{i m}\right]^{\alpha}\left[\eta_{i m}=\frac{S_{i m}}{L_{i m}}\right]^{\beta}} \quad \text { if } \quad j \in A C_{i} \\
\mathbf{0} \quad \text { Autre }
\end{array}\right.
$$

Move the $\mathrm{k}^{\text {th }}$ Ant to $\mathrm{j}$ \{This Instruction Creates a new value of $\left.\mathrm{b}_{\mathrm{j}}(\mathrm{t}+1)\right\}$

Insert the node $\mathrm{j}$ in $\operatorname{tabu}_{\mathrm{k}}(\mathrm{s})$.

STEP 3. For $\mathrm{k}:=1$ to $\mathrm{m}$ do $\{$ For each ant $\}$

Calculate $\mathrm{L}^{\mathrm{k}}$ \{Is the result of the tabu list\}

For $\mathrm{s}:=1$ to $\mathrm{n}-1$ do $\{\mathrm{scan}$ the tabu list of the $\mathrm{k}$-th Ant $\}$

$\operatorname{Set}(\mathrm{h}, \mathrm{l}):=\left(\mathbf{t a b u}_{\mathrm{k}}(\mathrm{s}), \mathbf{t a b u}_{\mathrm{k}}(\mathrm{s}+1)\right)$ 
$\{[\mathrm{h}, \mathrm{l}]$ it is the bow of connection of the node $\mathrm{s}$ and $\mathrm{s}+1$ in the tabu list of the Ant $\mathrm{k}$ \}

$\Delta \tau_{h, l}(t+n):=\Delta \tau_{h, l}(t+n)+\frac{Q}{L^{k}}$

$\mathrm{L}^{\mathrm{K}}$ : represents the length traveled by the Kth ant

Q: represents the amount of pheromone deposited by Kth ant.

STEP 4. For each bow $(i, j)$ calculate $\tau_{\mathrm{ij}}(\mathrm{t}+\mathrm{n})$ give to the equation (2)

Set $\mathrm{t}:=\mathrm{t}+\mathrm{n}$

For each bow $(\mathrm{i}, \mathrm{j})$ set $\Delta \tau_{\mathrm{ij}}(\mathrm{t}, \mathrm{t}+\mathrm{n}):=0$.

STEP 5. Remember the route found so far

If $\left(\mathrm{NC}<\mathrm{NC}_{\mathrm{MAX}}\right)$ or (Not all ants choose the same course) \{NC is the number of cycles of the algorithm; in NC cycles are test $\mathrm{NC} \cdot \mathrm{m}$ course $\}$

then

Empty all lists Tabu

Set $\mathrm{s}:=1$

For $\mathrm{i}:=1$ to $\mathrm{n}$ do

For $\mathrm{k}:=1$ to $\mathrm{b} \mathrm{i}(\mathrm{t}) \mathrm{do}$

$\operatorname{tabu}_{\mathrm{k}}(\mathrm{s}):=\mathrm{i}\{$ After the course of the k-th Fourmi is still on the starting position $\}$

\section{Goto STEP 2.}

else

Print the best course and do Stop.

\section{RESULTS}

The transport subsystem is usually based on medium voltage lines that supply medium voltage customers. Configurations are always tree-based. These lines are placed in parallel.

The following table shows the production characteristics of the HV transport network (table 1).

Table 1 Characteristics of High Voltage Production

\begin{tabular}{|c|c|c|c|}
\hline $\begin{array}{c}\mathrm{N}^{\circ} \text { of the } \\
\text { load }\end{array}$ & $\begin{array}{l}\text { coordinates } \\
\text { Cartesian x y }\end{array}$ & Rate of production & $\infty$ \\
\hline 1 & $50 \quad 50$ & $25 \% \quad 200$ & 00 \\
\hline 2 & $150 \quad 320$ & $25 \% \quad 200$ & \\
\hline 3 & $300 \quad 100$ & $25 \% \quad 200$ & $\sigma$ \\
\hline 4 & $350 \quad 200$ & $25 \% \quad 200$ & \\
\hline
\end{tabular}

Table 2 shows the Characteristics of High Voltage Production (220V).

Table 2 Characteristics of High Voltage load

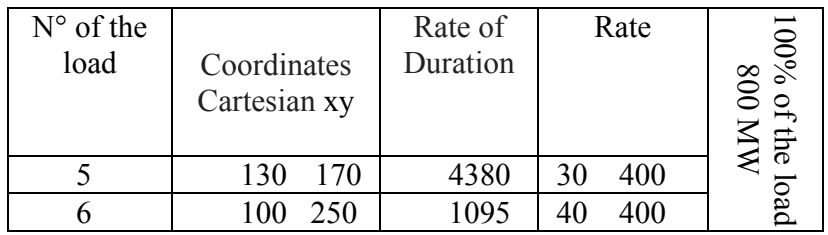

Table 3 Characteristics of Medium Voltage production

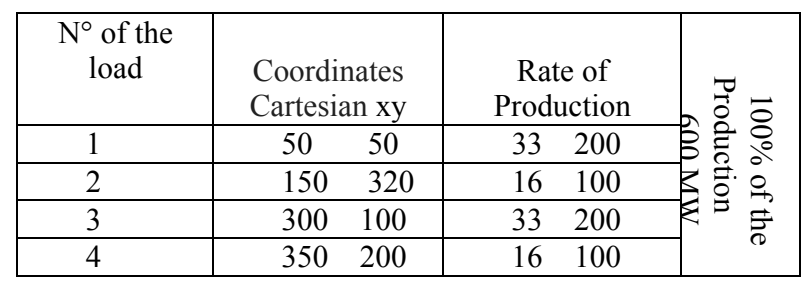

The following table (Table 4) shows the load characteristics of the MV transport network $(60 \mathrm{KV})$.

Table 4 Characteristics of the Medium Voltage load

\begin{tabular}{|c|c|c|c|c|}
\hline & & & Rate & \\
\hline $\begin{array}{l}\mathrm{N}^{\circ} \text { of } \\
\text { the load }\end{array}$ & $\begin{array}{l}\text { coordinates } \\
\text { Cartesian xy }\end{array}$ & $\begin{array}{l}\text { Duration } \\
\text { rate }\end{array}$ & & 용 \\
\hline 5 & $50 \quad 150$ & 1560 & $20 \quad 120$ & \\
\hline 6 & 100250 & 1560 & $10 \quad 60$ & \\
\hline 7 & 400300 & 2340 & $30 \quad 180$ & $\bar{D}$ \\
\hline 8 & $250 \quad 25$ & & $20 \quad 120$ & 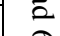 \\
\hline 9 & $150 \quad 125$ & & $20 \quad 120$ & 8 \\
\hline
\end{tabular}

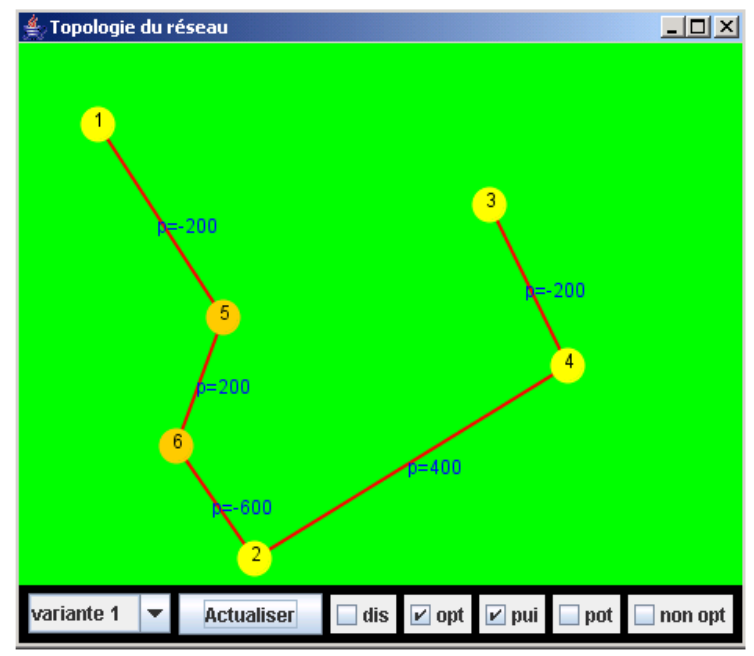

Fig. 9 Topology of the high voltage transport network

This interface shows the topology of the high voltage transport network, which can have a set of geometric and electrical parameters.

The paths (HT lines) that make up the optimal tree are $(1 \Rightarrow 5),(2 \Rightarrow 4),(2 \Rightarrow 6),(3 \Rightarrow 4),(5 \Rightarrow 6)$ 
This structure is obtained by the method of ant colonies, it represents a structure of a network of seven nodes including four producers and three consumers. This optimal structure concerns the HV distribution network that consumes $20 \%$ of the total load.

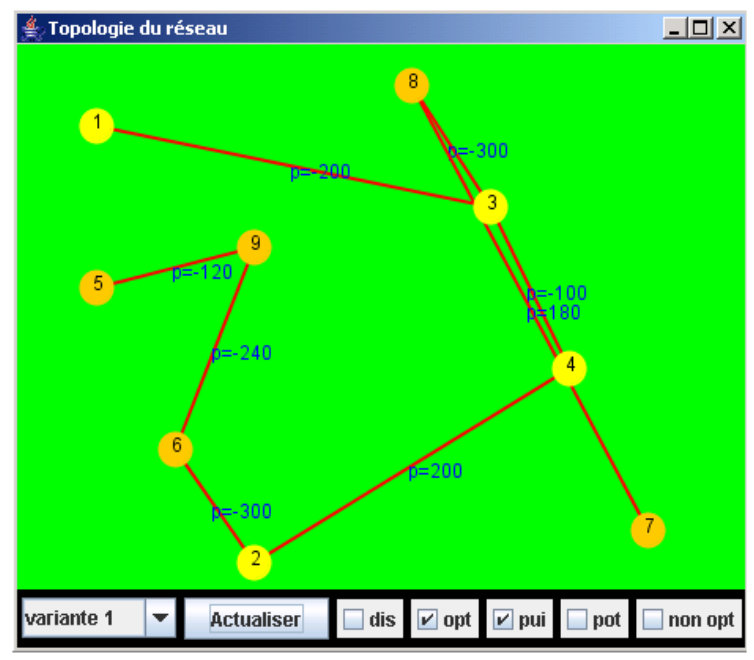

Fig. 10 Topology of the medium voltage network

This interface shows the topology of the medium voltage network of which we can have a set of geometrical and electrical parameters.

The paths (MV lines) that make up the optimal tree are:

$(1 \Rightarrow 5),(2 \Rightarrow 4),(2 \Rightarrow 6),(3 \Rightarrow 4)$

$(3 \Rightarrow 8),(5 \Rightarrow 9),(6 \Rightarrow 9),(7 \Rightarrow 8)$

his structure is obtained by the method of ant colonies, it represents a structure of a network of seven nodes including four producers and three consumers. This optimal structure concerns the MV distribution network that consumes $80 \%$ of the total load.

\section{CONCLUSION}

The ant colony method has been used in several areas including optimizing the power network. In our paper, a program (ANT-OPTI) has been designed for the optimization of the structures of the electricity transmission networks either High or Medium Voltage.

The result of the partial optimization on the high and medium voltage networks led us to optimal arborescent configurations.

The two optimal networks are in a more complex system of combinatorial problem with optimal allocation redundancy. This problem will be considered as a problem of RAP types (redundancy allocation problem). Their exact solutions involve combinatorial methods or metaheuristics.

\section{ACKNOWLEDGMENTS}

My thanks for professor Abdelhalim Benmansour, for having encouraged, reviewed, commented and corrected the article.

\section{REFERENCES}

[1] DREO, J. - PETROWSKI, A. - SIARRY, P. TAILLARD, E.: Méta-heuristiques pour l'optimisation difficile, Eyrolls, 2003.

[2] ZEBLAH, A. : Réalisation D'un Logiciel Pour La Reconstruction D'un Réseau Fiable Et sa Reconfiguration Optimale, thèse de doctorat, USTO, 2002.

[3] BOURI, S.: optimisation de la production et la structure d'énergie électrique par les colonies de fourmis, thèse de doctorat, Université Djilali Liabès, Faculté Des Sciences De l'Ingénieur, 2008.

[4] DORIGO, M.: Optimization, learning and natural algorithms, Ph.D. Thesis, Politecnico di Milano, Milano, 1992.

[5] CORDON, O. - FERNANDEZ DE VIANA, I. HERRERA, F. - MORENO, L.: A new ACO model integrating evolutionary computation concepts: the best-worst ant system, in Proceedings of ANTS2000 -from ant colonies to artificial ants, Universitè Libre de Bruxelles.

[6] MEZIANE, R.: Optimisation de la structure d'un réseau de production d'énergie électrique et amélioration de sa performance, thèse de doctorat, USTO 2007.

[7] MENDEZ, K. - SKOUNI, N.: Optimisation de la structure des réseaux de répartition en utilisant les algorithmes de fourmis, mémoire d'ingéniorat, Sidi Bel abbés 2006.

[8] ROUX, O.: La mémoire dans les algorithmes à colonie de fourmis : applications à l'optimisation et à la programmation automatique, thèse de doctorat de l'Université du Littoral Cote d'Opale, 2001.

[9] MANIEZZO, V. - DORIGO, M. - COLORNI, A.: The ant system: Optimization by a colony of cooperating agents. IEEE Transactions on Systems, Man, and Cybernetics-Part B, 26(1) :29-41, 1996.

[10] HABCHI, G. : «Conceptualisation et Modalisation pour les simulations de production», UNIVERSITE DE SAVOIE Document de Synthèse L.F. Escudero, An inexact algorithm for the sequential ordering problem. European Journal of Operational Research 37 (1988), 232-253 2001.

[11] MEZIANE, R. - MASSIM, Y. - ZEBLAH, A. GHORAF, A.: Reliability Computation For Algerian Power Network Considering Mss, An International Journal Of Nonlinear Dynamics And Chaos In Engineering Systems, Klewer Academic Publisher, Vol. 40, No. 4 june 2005, pp. 309321. 
[12] MEZIANE, R. - MASSIM, Y. - ZEBLAH, A. GHORAF, A. - RAHLI, M.: Reliability Optimization Using Ant Colony Under Cost and Performance Constraintes, Power System Research Journal ESRJ, 2005, Elsevier Publisher, Vol. N76, pp.1-8, 2005.

[13] ZEBLAH, A. - GHORAF, A. - HADJERI, S. HAMDAOUI, H.: Optimization for Series-Parallel Continuous Power Systems with Buffers Uder Reliability Constraints Using Ant Colony Accepted paper in international Journal of Industrial and Management Optimization, Vol. $\mathrm{N}^{\circ} 2$, Number 4, pp. 467-479 (JIMO) 2006.

[14] BULLNHEIMER, B. - HARTL, R. F. - STRAUSS, C.: A new rank-based version of the ant system: a computational study, Central European Journal of Operations Research 7 (1) (1999), 25-38.

[15] JIN-KAO HAO - GALINIER, P. - HABIB, M. : Méta heuristiques pour l'optimisation combinatoire et l'affectation sous contraintes, Revue d'Intelligence Artificielle, Vol. No. 1999.

[16] BENTLEY, J. L.: Fast algorithms for geometric traveling salesman problem, ORSA Journal on Computing, vol. 4, pp. 387-411, 1992.

[17] CAMARA, D. - LOUREIRO, A. A. F.: A GPS/antlike routing algorithm for ad hoc networks, in 2000 IEEE Wireless Communications and Networking Conference, Chicago, USA.

[18] DICARO, G. - DORIGO, M.: Antnet: distributed stigmergetic control for communications networks, Journal of Artificial Intelligence Research, 9 (1998), 317-365.

[19] DORIGO, M. - DI CARO, G. - GAMBARDELLA, L. M.: (1999). Ant Algorithms for Discrete Optimization. Artificial Life, 5(2):137-172.

[20] DORIGO, M. - GAMBARDELlA, L. M.: Ant colony system: a cooperative learning approach to the traveling salesman problem, IEEE Transaction on Evolutionary Computation 1(1997), 53-66.

[21] SCHATZ, B. - CHAMERON, S. - BEUGNON, G. - COLLET, T.: Path integration as a source of reinforcement signals for visual sequence learning in the ant Cataglyphis cursor., Nature, 399: 769-772, (1999).

[22] BOURI, S. - ZEBLAH, A. - GHORAF, A. HADJERI, S. - HAMDAOUI, H.: Ant Colony Optimization to Shunt Capacitor Allocation in Radial Distribution Systems Acta and Electronica et informatic journal Schekoslovacia No.4, Vol. 5; 2005.

[23] MEZIANE, R. - HAMDAOUI, H. - RAHLI, M. ZEBLAH, A.: Structure Optimization of Electrical Power Network Using Ant Colony Approach. Facta Univ. Ser.: Elec. Energ., Vol. 16, No. 2, August 2003, pp. 233-250.

[24] OUIDDIR, R. - RAHLI, M. - MEZIANE, R. ZEBLAH, A.: Ant colony Optimization For New Redesign Problem Of Multi-States Electrical Power
Systems. Journal Of Electrical Engineering, Vol. 55, $\mathrm{N}^{\circ}$ 1-2, 2004, pp. 1-7, ISSN 13-35-36-32.

[25] BONABEAU, E. - DORIGO, M. - THERAULAZ, G.: Nature, Vol. 406, No. 6791, Pag. 39 -42 (2000).

[26] MARTELLO, S. - OSMAN, I. H. - ROUCAIROL, C.: (eds.) Meta- Heuristics: Advances and Trends in Local Search Paradigms for Optimization, Kluwer, Boston, 1999.

[27] BIANCHI, L. - GAMBARDELLA, L. M. DORIGO, M.: An ant colony optimization approach to the probabilistic traveling salesman problem. In Proceedings of PPSN-VII, Seventh Inter17 national Conference on Parallel Problem Solving from Nature Science. Springer Verlag, Berlin, Germany, 2002.

[28] BULLNHEIMER, B. - HARTL, R. F. - STRAUSS, C.: Applying the ant system to the vehicle routing problem, In: Voss.

[29] BLUM, C. - SAMPELS, M.: Ant colony optimization for FOP shop scheduling: a case study on different pheromone representations, in Proceedings of the 2002 congress on Evolutionary Computation, Honolulu, USA.

[30] DEN BESTEN, M. - STÜTZLE, T. - DORIGO, M.: Ant colony optimization for the total weighted tardiness problem, Parallel Problem Solving from Nature: 6th international conference, September 2000. Springer Verlag.

[31] COLORNI, A. - DORIGO, M. - MANIEZZO, V.: Distributed optimization by ant colonies, Proceedings of ECAL'91, European Conference on Artificial Life, Elsevier Publishing, Amsterdam, 1991.

[32] DORIGO, M. - DI CARO, G.: (1999). The Ant Colony Optimization Meta-Heuristic. Numerical analysis Mac Grawhil Topic Computer science serie.

Received November 25, 2019, accepted March 24, 2020

\section{BIOGRAPHIES}

Bouri Sihem was born in Ain Témouchent (Algeria), on August 4, 1976. She graduated the Faculty of Technology, Sidi Bel Abess (Algeria), in 1999. She received the PhD degree in electrical engineering from the the Faculty of Technology, Sidi Bel Abess (Algeria), in 2008.

She is Professor at the Faculty of Technology, in Tlemcen (Algeria). Her research interests concern: power systems, reliability, Universal moment generating Function (UMGF).

Abdelhalim Benmansour was born on January 2, 1957 in Tlemcen (Algeria). He graduated from the University of Sciences and Technology of Algiers in Physics in 1979 and from the National School of Electrical Engineers (ENSIEG) of the National Polytechnic Institute (INPG) of Grenoble (France) in electrical engineering in 1982. He 
obtained his energetic magister in 1992 and his $\mathrm{PhD}$ in energies (URMER) at the University of Tlemcen (Algeria). materials science in 2004 at the University of Tlemcen His research interests include: photovoltaic cells, materials, (Algeria). He is professor at the faculty of technology and renewable energy and water treatment. director of the research unit on materials and renewable 